\title{
Field Emission Characteristics of Metal-doped Nano- diamond Cathode on Titanium Substrate
}

\author{
Yang Yanning ${ }^{1}, \quad$ Li Weixia $^{1}, \quad$ Zhang Zhiyong $^{2}, \quad$ Zhai Chunxue $^{2}, \quad$ Liu Qiaoping ${ }^{1}$ \\ ${ }^{1}$ Yan'an University, Yan'an 716000, China; ${ }^{2}$ Northwest University, Xi'an 710127, China
}

\begin{abstract}
Field emission characteristics of metal-doped nano-diamond on titanium substrate were studied, wherein metals—-Ti and Hf were mixed with nano-diamond separately, and cathode samples were prepared by electrophoresis. Then the structures and morphologies of cathode samples were characterized by SEM and XRD; finally, field emission tests were conducted. Results show that the morphology of $5 \mathrm{mg}$ Ti-doped sample is more uniform and dense, but the morphologies of Hf-doped samples become worse. Meanwhile, compared with the undoped sample, field emission characteristics of Ti-doped samples improve, while those of Hf-doped samples decrease. From the comparison between Ti-doped samples, it is found that the amount of Ti mixed with nano-diamond should not be too much; a moderate amount of Ti can improve field emission characteristics of nano-diamond on Ti substrate. It is determined by the nature of metal $\mathrm{Ti}$ and $\mathrm{Hf}$, which influences the bonding reaction between nano-diamond and substrate Ti, thus affecting, field emission characteristics of doped nano-diamond on Ti substrate.
\end{abstract}

Key words: nano-diamond; metals; SEM; XRD; field emission characteristics

In recent years, carbon-based composites prepared by substrates of carbon materials such as nano-diamond and CNT have become one hot topic of materials research ${ }^{[1]}$, which are mainly prepared by methods of doping, mixing, cladding and modification ${ }^{[2,3]}$. For example, Chong et al ${ }^{[4]}$ pointed out that field emission characteristics of diamond-like carbon nanodot arrays after doping are better obviously than undoped. Zeng et al ${ }^{[5]}$ studied on field emission characteristics of diamond/Ag composites and pointed out that electron emission area is formed at the interface of $\mathrm{Ag}$ and diamond because of the existence of $\mathrm{Ag}$, so field emission characteristics of diamond/Ag composites improve. On the other hand, variations of surface morphologies and structures after doping, mixing, cladding or modification can change field enhancement factor of materials surface ${ }^{[6]}$, and all changes are helpful to improve field emission characteristics of nano-diamond. When heat treatment of nano-diamond cathode samples on titanium substrate is carried out, a solid-phase bonding reaction between diamond and metal $\mathrm{Ti}$ occurs and easily-conductive $\mathrm{TiC}$ is generated when temperature is above $400{ }^{\circ} \mathrm{C}^{[7,8]}$. Metal Hf has good inoxidizability, good conductivity and thermal conductivity, lower work function; therefore, it is always used as plasma emitters of plasma cutting electrical machines and sputtering target ${ }^{[6]}$. Meanwhile, carbide of $\mathrm{Hf}$ ( $\mathrm{HfC}$ ) is widely used in spaceflight and flat-panel display realm as high-temperature structural material. Therefore, metal $\mathrm{Ti}$ and Hf are selected as doping materials in the present paper and their field emission characteristics are compared; meanwhile, the influence of metals on field emission characteristics of nano-diamond on Ti substrate is studied.

\section{Experiment}

Before electrophoretic deposition, Ti substrates must be ground, polished, and cleaned by detergent, and ultrasonic and rinsed with deionized water. Then they are reserved to be used after ethanol dehydration reaction.

The technical progress of preparing electrophoretic liquid

Foundation item: Ph. D., Start-up Foundation of Yan'an University (YD 2010-04); Special Foundation of Yan'an University (YDZD 2011-01); 2014 Education and Innovation Project of Yan'an University for Graduate Student; 2014 Local University National Training Project of Innovation and Entrepreneurship for Undergraduates (201410719023)

Corresponding author: Zhang Zhiyong, Ph. D., Professor, Information Science and Technology Institution, Northwest University, Xi'an 710127, P. R. China, Tel: 0086-29-88308820, E-mail: zhangzy@nwu.edu.cn 
was as follows: mixing nano-diamond powder $20 \mathrm{mg}$, iodine $20 \mathrm{mg}$, acetone $1 \mathrm{~mL}$, is obutanol $40 \mathrm{~mL}$ and deionized water $2 \mathrm{~mL}$ into 7 beakers separately, and they were named sample 1 7. Wherein sample 1 was undoped diamond; sample 2 4 were diamond doped with 2,5 and $10 \mathrm{mg}$ Ti powder (the average grain size of Ti powder was $40 \mathrm{~nm}$ and purity $99.9 \%$ ), respectively; and sample 5 7 were diamond doped with 2, 5 and $10 \mathrm{mg}$ Hf powder (the average grain size of $\mathrm{Hf}$ powder was $1 \mu \mathrm{m}$ and purity $99.9 \%$ ) respectively.

After uniform solutions were prepared, they were placed in the ultrasonic cleaner to conduct ultrasonic diffusion for 60 min at ultrasonic temperature $50{ }^{\circ} \mathrm{C}$. After ultrasonic diffusion was finished, electrodes were placed into electrophoretic liquid to begin electrophoresis the space between cathode and anode $1 \mathrm{~cm}$, electrophoresis voltage $60 \mathrm{~V}$, and time $1 \mathrm{~min}$. Then deposited samples were placed into Hot Filament Chemical Vapor Deposition (HFCVD) to carry out heat treatment, whose temperature was $800{ }^{\circ} \mathrm{C}$, and time was 10 min. Wherein the thickness of typical Ti-doped samples and Hf-doped samples was $601.50 \mathrm{~nm}$ and $1.36 \mu \mathrm{m}$, respectively.

Finally, field emission characteristics tests were conducted.
In the field emission tester, diode-type structure was adopted, the anode was glass coated with ITO transparent conductive thin film, and the cathode was prepared samples, while the space between two poles was about $200 \mu \mathrm{m}$. When vacuum degree reached $10^{-4} \mathrm{~Pa}$ level, DC regulated power supply was adjusted to test field emission ${ }^{[6]}$.

\section{Results and Discussion}

\subsection{Morphologies of cathode samples}

Fig.1 shows SEM morphologies of all samples after heat treatment. Fig.1a 1d are SEM morphologies of sample 1 4, indicating that surface morphologies of Ti-doped samples change a lot after heat treatment, some larger aggregates appear on the surface and the surface becomes complex; comparatively speaking, the surface of sample 3 doped with 5 $\mathrm{mg}$ Ti powder is more uniform and denser. Fig.1e 1g are SEM morphologies of sample 5 7. Obviously, the surface morphologies become worse and worse as the amount of doped Hf increases.

\subsection{Characterization of cathode samples}

XRD patterns of sample 1.3 and 6 are given in Fig.2. It can

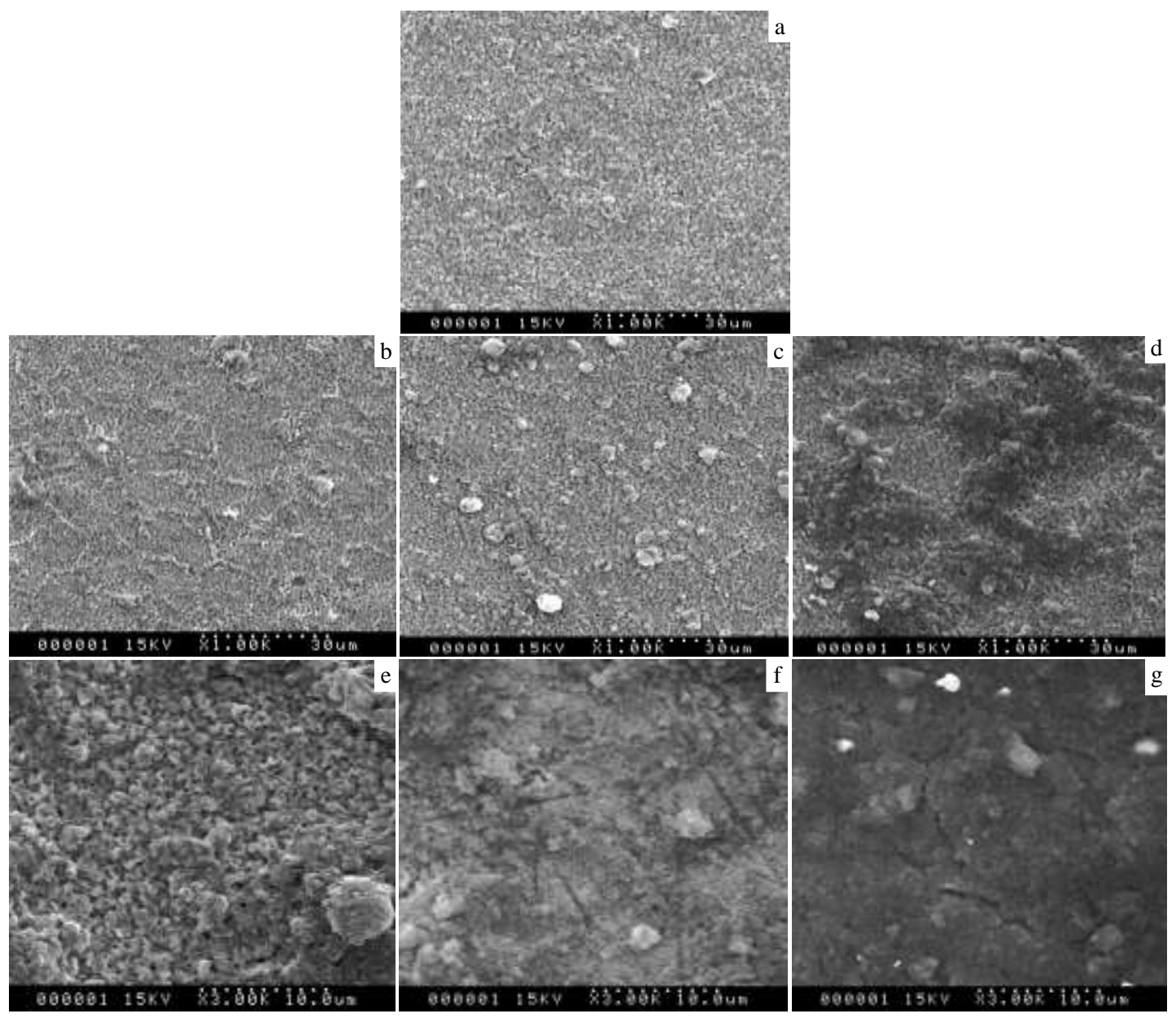

Fig.1 SEM morphologies of each sample after heat treatment: (a) sample 1, (b) sample 2, (c) sample 3, (d) sample 4, (e) sample 5, (f) sample 6, and (g) sample 7 

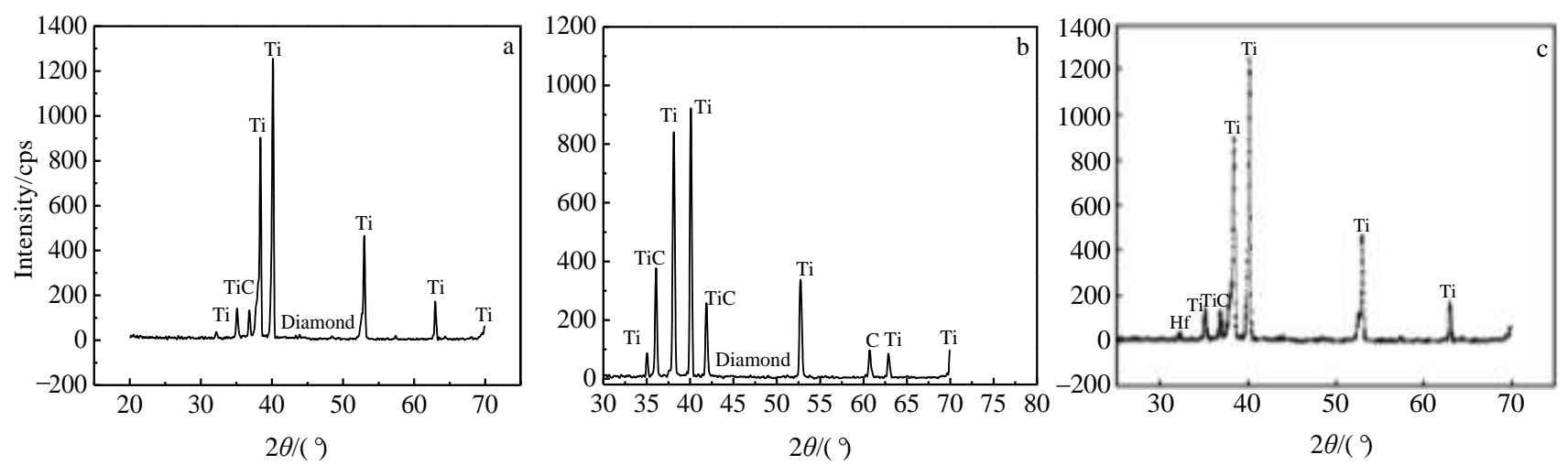

Fig.2 XRD patterns of sample 1 (a), 3 (b), 6 (c) after heat treatment

be seen from the patterns that diffraction peaks of $\mathrm{TiC}$ located at about $36.08^{\circ}$ of three samples all appear, because the bonding reaction occurs between nano-diamond particles of three samples' coating and substrate $\mathrm{Ti}$ in the process of heat treatment and good bonding is realized ${ }^{[9,10]}$. And in Fig.2b, because the reaction between $\mathrm{Ti}$ and diamond is enhanced, the intensity of $\mathrm{TiC}$ diffraction peaks strengthens. However, in Fig.2a and 2c, TiC diffraction peaks almost don't change. Meanwhile, because Ti is substrate, diffraction peaks of Ti can also be seen in all samples' patterns. Moreover, in sample 1, weak diffraction peaks of diamond and $\mathrm{C}$ appear; only diffraction peaks of $\mathrm{TiC}$ and $\mathrm{Ti}$ occur in sample 3, which shows that there aren't other elements and compounds in the sample. Since little amount of nanoscale diamond is used, the diffraction peak of nano-diamond is very weak. Whereas in sample 6, not only diffraction peaks of $\mathrm{TiC}$ and $\mathrm{Ti}$ appear, but also Hf occurs. Comparatively speaking, diffraction peaks of $\mathrm{Hf}$ and $\mathrm{TiC}$ are weak.

\subsection{Results and analysis of field emission tests}

Fig.3, Fig.4 give field emission characteristics curves of samples, with system vacuum degree $2.2 \sim 2.6 \times 10^{-4} \mathrm{~Pa}$. From $I-V$ characteristics curves of Fig. 3 a, turn-on field of undoped sample 1 is about $7.45 \mathrm{~V} / \mu \mathrm{m}$, current density is about 36.00 $\mu \mathrm{A} / \mathrm{cm}^{2}$ at the field strength of $13.80 \mathrm{~V} / \mu \mathrm{m}$; and turn-on field of sample $2 \sim 4$ is $6.95,6.45,5.95 \mathrm{~V} / \mu \mathrm{m}$, respectively, and field emission current density is $60,74,122 \mu \mathrm{A} / \mathrm{cm}^{2}$, respectively at the same field strength. F-N curves are approximately linear, which confirm field emission mechanism of each sample ${ }^{[11,12]}$. Fig. $3 b$ shows that with the increasing amount of doped Hf, turn-on field becomes larger and larger, while current density becomes smaller. And the slope of F-N curves also gets large compared with that of the undoped diamond, All indicate after Hf doping, field emission characteristics decline. Consequently, for the same amount of doped Ti and Hf, field emission characteristics of Ti-doped samples on Ti substrate are better than those of Hf-doped samples.

For undoped diamond, only Ti-TiC-Diamond layer structure ${ }^{[13]}$ can be formed on the cathode surface after heat treatment and
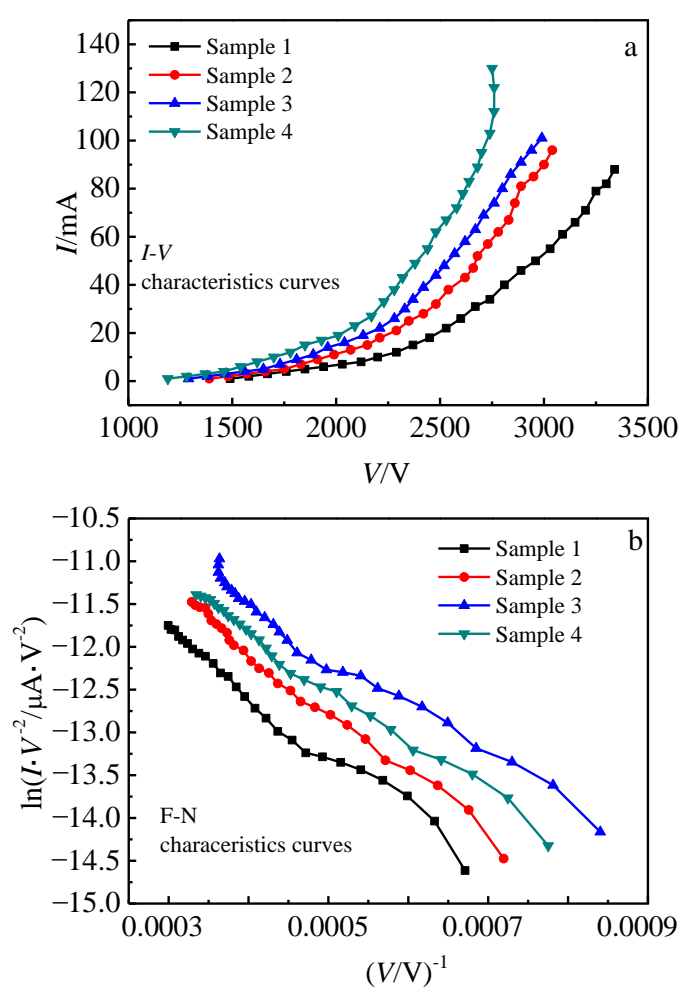

Fig.3 Field emission characteristics of samples 1, 2, 3, and 4: (a) $I-V$ and (b) F-N

a large number of diamond particles will overlap; however, the conductivity of diamond itself is inferior, which leads to the difficult transportation of electrons to the coating surface $^{[14]}$; therefore, field emission current is relatively low. Whereas electrophoresis liquid of sample 3 doped with $5 \mathrm{mg}$ $\mathrm{Ti}$ is diffused uniformly, the overlap of diamond particles of deposited cathode surface is decreased. After heat treatment, the bonding reaction not only occurs between $\mathrm{Ti}$ substrate and diamond particles, but also occurs between Ti powder and diamond particles of coating; therefore, the network structure of Ti-TiC-diamond-TiC-Ti is formed ${ }^{[13,15]}$, which greatly enhances electron transportation capacity of coating. Diamond emitters 

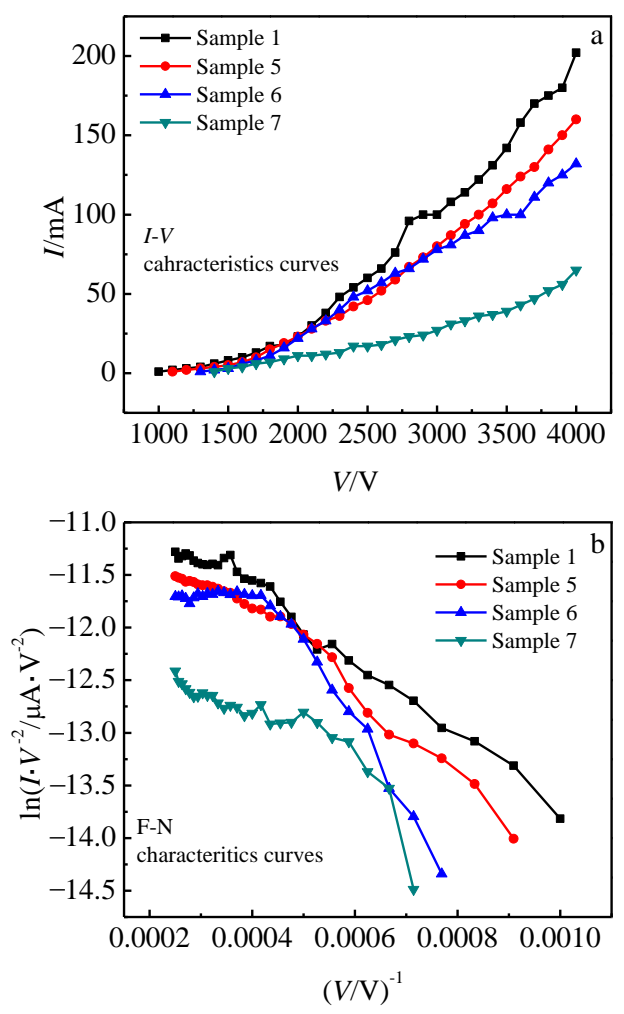

Fig.4 Field emission characteristics of samples 1, 5, 6, and 7: (a) $I-V$ and (b) F-N

are embedded in the network structure, thus reducing the existence of isolated diamond particles and diamond particles on the surface become effective emitters as far as possible. What's more, the network structure of the coating, highdensity dangling bonds, defects and impurities are all helpful to enhance field electron emission ${ }^{[16-18]}$, and in the process of impressed voltage, field emission current increases and the stability enhances. However, if excessive Ti is doped, a lot of aggregates of $\mathrm{Ti}$ and diamond particles occur on the sample surface, and the conductivity of $\mathrm{Ti}$ and $\mathrm{TiC}$ is better than diamond; therefore, the conductivity capacity of coating improves, thus increasing current density, but the number of effective diamond emitters decreases on the sample surface because of aggregation. Meanwhile, a large amount of doped Ti strengthens the shielding effect, field emission characteristics become bad, so the shielding effect can be reduced by controlling the amount of doped Ti. Therefore, a certain amount of doped $\mathrm{Ti}$ can improve field emission characteristics of nano-diamond on titanium substrate.

However, for Hf-doped samples, because $\mathrm{Hf}$ is a kind of high-stability metal, at the heat treatment temperature of $800{ }^{\circ} \mathrm{C}$, the bonding reaction doesn't occur between $\mathrm{Hf}$ and $\mathrm{Ti}$ substrate; meanwhile, Hf also influences the bonding reaction between diamond and Ti substrate. Therefore, field emission characteristics of Hf-doped diamond samples on Ti substrate don't improve but decline.

\section{Conclusions}

1) In the preparation process of field emission cathode samples of nano-diamond by electrophoretic deposition, doping the right amount of $\mathrm{Ti}$ powder can enable better diffusion of electrophoresis solution; therefore, the deposited nano-diamond coating is more uniform and finer. However, doping Hf powder worsens the deposited nano-diamond coating become.

2) Doping moderate $\mathrm{Ti}$ powder can form TiC buffer layers, which enhance the electronic transportation capacity, thereby greatly improving the field emission characteristics for doping too much $\mathrm{Ti}$, a lot of $\mathrm{TiC}$ is generated, thus covering the surface diamond particles, decreasing the effective emitters and declining the field emission characteristics, because $\mathrm{Hf}$ influences the bonding reaction between diamond particles and Ti substrate.

3) Doping moderate $\mathrm{Ti}$ can improve field emission characteristics improve, while doping Hf can't enhance field emission characteristics of nano-diamond on Ti substrate.

\section{References}

1 Ma L A, Hu L Q, Guo T L. Chinese Journal of Liquid Crystals and Displays[J], 2008, 23: 357 (in Chinese)

2 Baral B, Foord J S, Jackman R B. Diam Relat Mater[J], 1997, 6(5-7): 867

3 Li J J, Zheng W T, Gu C Z et al. Material Science \&Processing: Appl Phys A[J], 2005, 81(2): 357

4 Chong E M, Li X C, Li C et al. Journal of Synthetic Crystals[J], 2008, 37(1): 29

5 Zeng L Y, Wang W B, Liang J Q et al. Chinese Journal of Crystals and Displays[J], 2007, 22(2): 13 (in Chinese)

6 Yang Y N. Thesis for Doctorate[D]. Xi' an: Northwest University, 2010 (in Chinese)

7 Tachibana T, Williams B E, Glass J T. Phys Rev B[J], 1992, 45(20): 11975

8 Liang X B, Jia C C, Chu K et al. Journal of Composite Materials [J], 2012, 46(9): 1127

9 Qian K Y. Material Review[J], 2004, 18: 12 (in Chinese)

10 Zhang C Z, Tang Y, Li Y S et al. Thin Solid Films[J], 2013, 528(3): 111

11 Yan J K, Chang L. Thin Solid Films[J], 2006, 498(1): 230

12 Chang $\mathrm{T} \mathrm{H}$, Panda K, Panigrahi B K et al. The Journal of Physical Chemistry C[J], 2012, 116(37): 19867

13 Yang Y N, Zhang Z Y, Zhang F C et al. Chin Phys Lett [J], 2012, 29(10): 018103

14 Pfeiffer R, Kuzmany H, Knoll P et al. Diamond Related Materials[J], 2003, 82(3): 268

15 Zhai C X, Zhang Z Y, Wang X W et al. Acta Photonica Sinica[J], 2007, 36(1): 30 (in Chinese)

16 Jia L, Lv Z, Zhi Z et al. Chinese Journal of Power Sources[J], 2005, 129: 274 (in Chinese) 


\title{
钛基金属掺混纳米金刚石阴极的场发射特性
}

\author{
杨延宁 ${ }^{1}$, 李伟霞 ${ }^{1}$, 张志勇 ${ }^{2}$, 翟春雪 ${ }^{2}$, 刘巧平 ${ }^{1}$ \\ (1. 延安大学, 陕西 延安 716000) \\ (2. 西北大学, 陕西 西安 710127)
}

\begin{abstract}
摘 要: 研究了钛基金属掺混纳米金刚石的场发射特性。以铁和铪分别和纳米金刚石掺混, 采用电泳法制得了阴极样品, 并使用 SEM 和 XRD 对阴极样品的结构和形貌进行表征, 最后进行场发射特性的测试。结果发现, 掺入 $5 \mathrm{mg}$ 的钛样品的形貌更加均匀和致密, 而掺 入铪样品的形貌变差。同时, 与未掺杂样品相比较而言, 掺钦样品的场发射特性有了提高, 而掺铪样品的场发射特性有所下降。掺钠样 品之间的比较发现, 钛掺入量不宜过多, 适量的钣掺入能使得纳米金刚石阴极的场发射性能得到提高。分析表明, 这是由金属铁和铪的 性质决定的，影响了金刚石与基底 $\mathrm{Ti}$ 的键合反应，从而影响了掺杂纳米金刚石的场发射性能。
\end{abstract}

关键词: 纳米金刚石; 金属; SEM; XRD; 场发射特性

作者简介: 杨延宁, 男, 1969 年生, 博士, 教授, 延安大学物理与电子信息学院, 陕西 延安 716000, E-mail: yayyn@163.com 